09,12

\title{
Модификация наночастиц оксида церия при облучении ускоренными электронами
}

\author{
() И.Н. Бажукова ${ }^{1}$, А.В. Мышкина ${ }^{1}$, С.Ю. Соковнин ${ }^{1,2}$, В.Г. Ильвес ${ }^{2}$, А.Н. Киряков ${ }^{1}$, \\ С.И. Бажуков ${ }^{1}$, Р.А. Вазиров ${ }^{1}$, В.В. Касьянова ${ }^{1}$, И.А. Звонарева ${ }^{1}$ \\ ${ }^{1}$ Уральский федеральный университет, \\ Екатеринбург, Россия \\ ${ }^{2}$ Институт электрофизики УрО РАН, \\ Екатеринбург, Россия \\ E-mail: i.n.sedunova@urfu.ru
}

В работе выполнено исследование люминесцентно-оптических свойств наночастиц оксида церия $\left(\mathrm{CeO}_{2}\right)$, облученных ускоренными электронами с энергией $10 \mathrm{MeV}$. Наночастицы $\mathrm{CeO}_{2}$ получены методом импульсного электронного испарения керамической мишени с конденсацией паров испаряемого материала в газе низкого давления на установке НАНОБИМ-2. Обнаружено, что при облучении нанопорошков $\mathrm{CeO}_{2}$ происходит деградация люминесцентно-оптических свойств материала. Облучение готовой водной суспензии по сравнению с облучением нанопорошка приводит к сдвигу полосы фотолюминесценции в длинноволновую часть спектра. Проведено исследование каталазаподобного поведения наночастиц $\mathrm{CeO}_{2}$ при взаимодействии с перекисью водорода. Модификация наночастиц электронным пучком приводит к уменьшению ферментноподобной активности материала.

Работа поддержана грантом РНФ № 18-72-00041.

DOI: 10.21883/FTT.2019.05.47604.16F

\section{1. Введение}

Нанокристаллический оксид церия $\mathrm{CeO}_{2}$ представляет собой перспективный объект для различных приложений, в том числе биомедицинских задач [1-5]. Значительный интерес к изучению данного объекта обусловлен тем, что при переходе в наноразмерное состояние оксид церия изменяет свои физико-химические свойства. Предполагается, что это связано с изменением электронной структуры материала, образованием кислородных вакансий из-за увеличения доли атомов, находящихся на поверхности частиц, и, как следствие, изменением кислородной нестехиометрии [1]. Образование кислородных вакансий приводит к тому, что на поверхности наночастиц ионы $\mathrm{Ce}^{4+}$ восстанавливаются до состояния $\mathrm{Ce}^{3+}$. Подобная кислородная нестехиометрия коррелирует с каталитической активностью наночастиц оксида церия и отвечает за их уникальную биологическую активность [6].

Большое количество исследований посвящено изучению способности наночастиц оксида церия выполнять функции антиоксидантов, имитируя поведение ряда ферментов - каталазы, супероксиддисмутазы $[7,8]$. Причем обнаружено, что данная активность возрастает при увеличении валентного соотношения $\mathrm{Ce}^{3+} / \mathrm{Ce}^{4+}$ на поверхности наночастиц. Таким образом, можно предположить, что присутствие ионов $\mathrm{Ce}^{3+}$ в поверхностном слое наночастицы играет ключевую роль в инактивации свободных радикалов, и валентное соотношение $\mathrm{Ce}^{3+} / \mathrm{Ce}^{4+}$ является одним из важнейших параметров, определяющих биологическую активность материала. Поэтому возможность контроля и управления данным параметром представляет интерес для исследования.
На сегодняшний день опубликован ряд работ, посвященных определению данного соотношения разными методами $[9,10]$. В работе [11] была показана возможность косвенного определения валентного соотношения $\mathrm{Ce}^{3+} / \mathrm{Ce}^{4+}$ с помощью люминесцентных методов анализа. Предполагается, что изменение кислородной стехиометрии и образование $\mathrm{Ce}^{3+}$ будет вызывать изменение оптических и люминесцентных свойств наночастиц оксида церия [11]. Несмотря на повышенный интерес к данному соединению, работы по исследованию люминесцентных свойств наночастиц оксида церия немногочисленны, но их результаты свидетельствуют о возможности определения валентного соотношения $\mathrm{Ce}^{3+} / \mathrm{Ce}^{4+}$ спектроскопическими методами [12].

Систематические исследования в области управления кислородной нестехиометрией наночастиц оксида церия отсутствуют. Опубликованы отдельные работы по модификации наночастиц $\mathrm{CeO}_{2}$ разными методами: с помощью отжига оксидов в восстановительных или нейтральных средах $[11,13]$, легирования матрицы [14], облучения ионизирующим излучением [15-17]. В ряде работ отмечают возможность создания кислородных вакансий и изменения люминесцентно-оптических свойств материалов. Однако анализу корреляции модифицированных свойств и проявляемой биологической активности не уделяется много внимания.

Целью настоящей работы является исследование люминесцентно-оптических свойств нанопорошков оксида церия $\mathrm{CeO}_{2}$, модифицированных ускоренными электронами с энергией $10 \mathrm{MeV}$, и установление корреляции между данными свойствами и биологической активностью материала. 


\section{2. Детали эксперимента}

Наночастицы оксида церия $\mathrm{CeO}_{2}$ были получены методом импульсного электронного испарения керамической оксидной мишени с конденсацией паров испаряемого материала в газе низкого давления на установке НАНОБИМ-2. Детали синтеза материала подробно описаны в работе [18]. Средний размер зерен наночастиц составляет 3-5nm, их форма близка к сферической полиэдральной, удельная поверхность составляет около $190 \mathrm{~m}^{2} / \mathrm{g}[19]$.

Модификацию наночастиц $\mathrm{CeO}_{2}$ электронным пучком проводили на линейном ускорителе электронов УЭЛР-10-10С (Уральский федеральный университет, ИВЦ Радиационной стерилизации). Для определения поглощенной дозы и контроля облучения использовались дозиметры на основе сополимера с феназиновым красителем СО ПД(Ф)Э-5/50. Облучение наночастиц проводилось в двух режимах: облучение нанопорошков с последующим приготовлением на их основе суспензий и облучение непосредственно готовых водных суспензий наночастиц.

Для исследования люминесцентно-оптических свойств были использованы суспензии наночастиц. Методика их приготовления заключалась в следующем. Наночастицы диспергировали в дистиллированной воде в концентрации $200 \mathrm{mg} / \mathrm{ml}$. В качестве стабилизатора суспензий использовали соль лимонной кислоты (цитрат натрия $\left.\mathrm{Na}_{3} \mathrm{C}_{6} \mathrm{H}_{5} \mathrm{O}_{7}\right)$. Суспензии наночастиц тщательно перемешивали и обрабатывали ультразвуком в течение $40 \mathrm{~min}$. Размер агломератов наночастиц в суспензии и дзета-потенциал раствора измеряли с использованием системы ZetasizerNano ZS (Malvern).

Измерение спектров оптического поглощения проводили с помощью спектрофотометра Helios Alpha $(\lambda=190-1000 \mathrm{~nm})$, оснащенного программным обеспечением Vision 32. Расчет ширины запрещенной зоны нанокристалла производился графическим методом Тауца [20].

Исследование люминесцентных свойств наночастиц проводили с помощью флуоресцентного спектрометра LS 55 (Perkin Elmer). В качестве источника возбуждения использовали импульсную ксеноновую лампу.

Каталазаподобную активность наночастиц $\mathrm{CeO}_{2}$ исследовали путем измерения оптического поглощения суспензий до и после добавления перекиси водорода с концентрацией $20 \mathrm{mmol} / 1$. Значение кислотности суспензии $p \mathrm{H}$ измеряли с помощью $p \mathrm{H}$-метра KELILONG PH-009.

\section{3. Результаты эксперимента}

На рис. 1 приведены спектры оптического поглощения суспензий наночастиц оксида церия (концентрация $\mathrm{CeO}_{2} 200 \mathrm{mg} / \mathrm{ml}$ ), измеренные при температуpe $293 \mathrm{~K}: 1$ - необлученный образец, 2-4 - образцы, облученные перед приготовлением суспензий дозами 12.5, 25 и $50 \mathrm{kGy}$ соответственно. В области

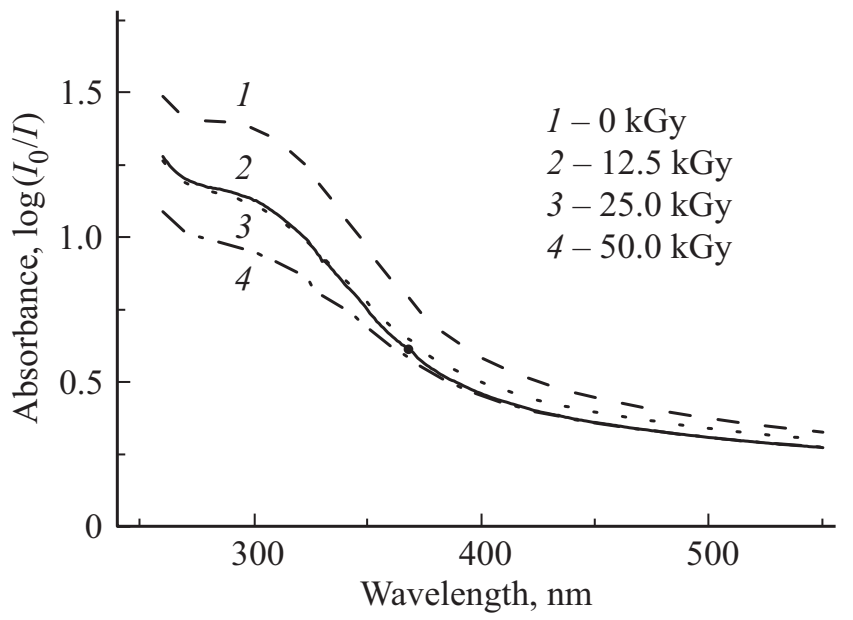

Pис. 1. Спектры оптического поглощения суспензий наночастиц $\mathrm{CeO}_{2}: 1$ - необлученный образец (штриховая линия), 2-4 - образцы, облученные перед приготовлением суспензий дозами $12.5 \mathrm{kGy}$ (сплошная линия), $25 \mathrm{kGy}$ (пунктирная линия) и $50 \mathrm{kGy}$ (штрих-пунктирная линия) соответственно.
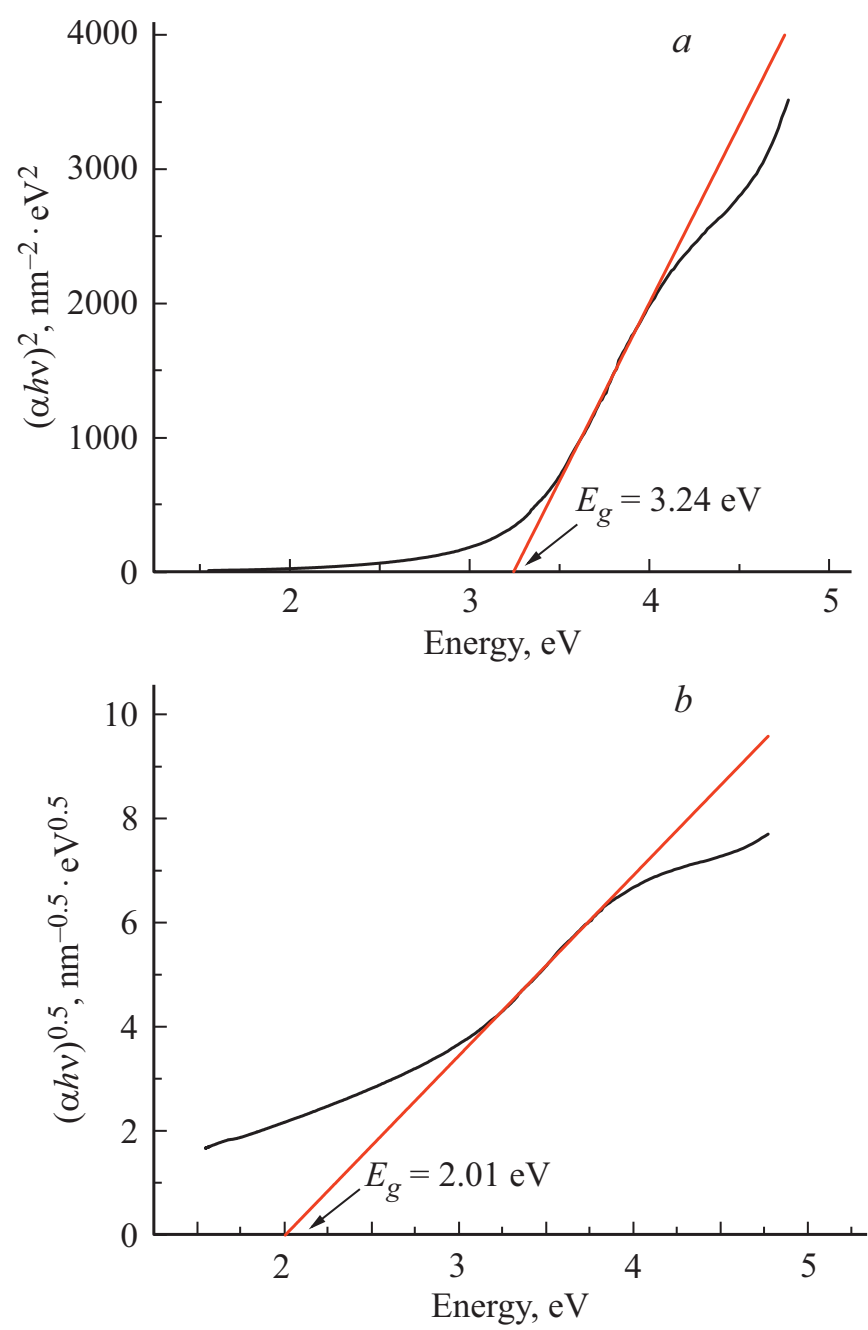

Рис. 2. Оценка ширины запрещенной зоны для прямых $(a)$ и непрямых переходов $(b)$ в наночастицах $\mathrm{CeO}_{2}$ (необлученный образец). 


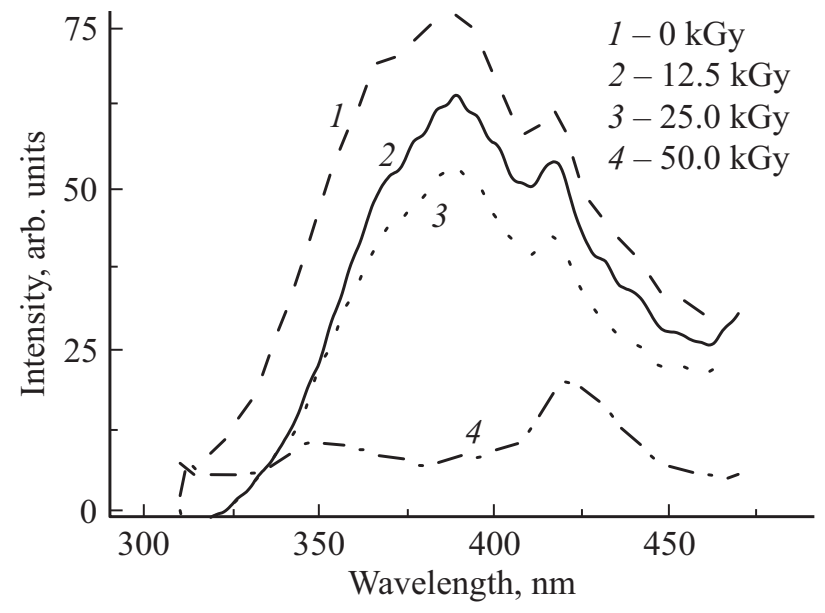

Рис. 3. Спектры фотолюминесценции суспензий наночастиц $\mathrm{CeO}_{2}$ при возбуждении $\lambda_{\mathrm{ex}}=250 \mathrm{~nm}: 1-$ необлученный образец (штриховая линия), 2-4 - образцы, облученные перед приготовлением суспензий дозами $12,5 \mathrm{kGy}$ (сплошная линия), $25 \mathrm{kGy}$ (пунктирная линия) и $50 \mathrm{kGy}$ (штрих-пунктирная линия) соответственно.

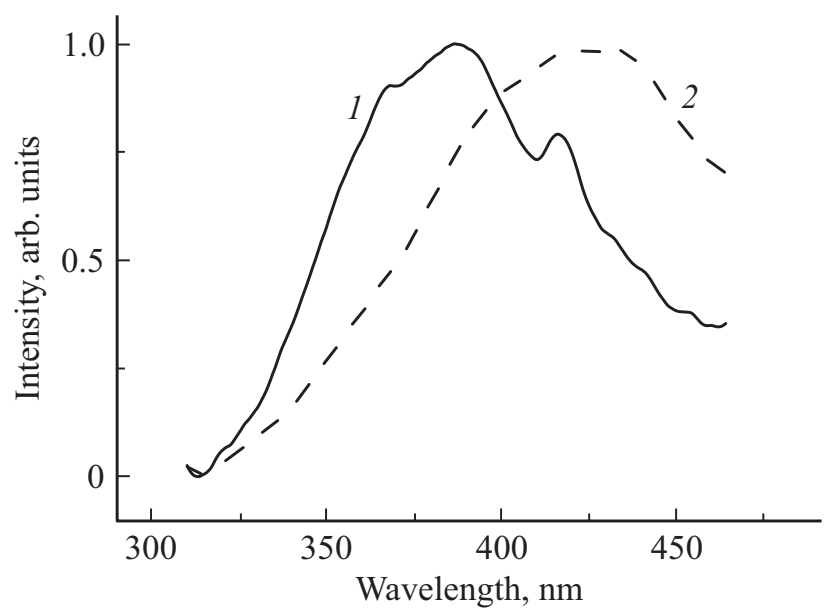

Рис. 4. Нормированные спектры ФЛ суспензий наночастиц $\mathrm{CeO}_{2}$, измеренные для разных режимов облучения дозой $25 \mathrm{kGy:} 1$ - водная суспензия, приготовленная из заранее облученного нанопорошка, 2 - облученная водная суспензия.

250-500 nm для всех образцов наблюдается широкая интенсивная полоса поглощения с максимумом в области 300-320 nm, которая, вероятно, связана с фотоиндуцированными оптическими переходами с переносом заряда с $2 p$-орбитали кислорода на незаполненную $4 f$-орбиталь иона $\mathrm{Ce}^{4+}[21]$. С увеличением дозы облучения наблюдается уменьшение величины оптической плотности образца.

На рис. 2 представлены результаты графического определения ширины запрещенной зоны $E_{g}$ в случае прямых и непрямых переходов для необлученного образца. В таблице приведены результаты расчетов для всех образцов.

На рис. 3 приведены спектры фотолюминесценции (ФЛ) суспензий наночастиц оксида церия, измеренные
Результаты расчета ширины запрещенной зоны для прямых и непрямых переходов в облученных и необлученных нанопорошках оксида церия

\begin{tabular}{c|c|c|c|c}
\hline Параметр & $0 \mathrm{kGy}$ & $12.5 \mathrm{kGy}$ & $25 \mathrm{kGy}$ & $50 \mathrm{kGy}$ \\
\hline Прямые переходы $E_{g}, \mathrm{eV}$ & 3.24 & 3.27 & 3.23 & 3.10 \\
Непрямые переходы $E_{g}, \mathrm{eV}$ & 2.01 & 2.09 & 1.94 & 1.80
\end{tabular}

при возбуждении $\lambda_{\mathrm{ex}}=250 \mathrm{~nm}: 1-$ необлученный образец, 2-4 - образцы, облученные перед приготовлением суспензий дозами $12.5,25$ и $50 \mathrm{kGy}$ соответственно. В видимой области спектр люминесценции представлен широкой неэлементарной полосой ФЛ, простирающейся
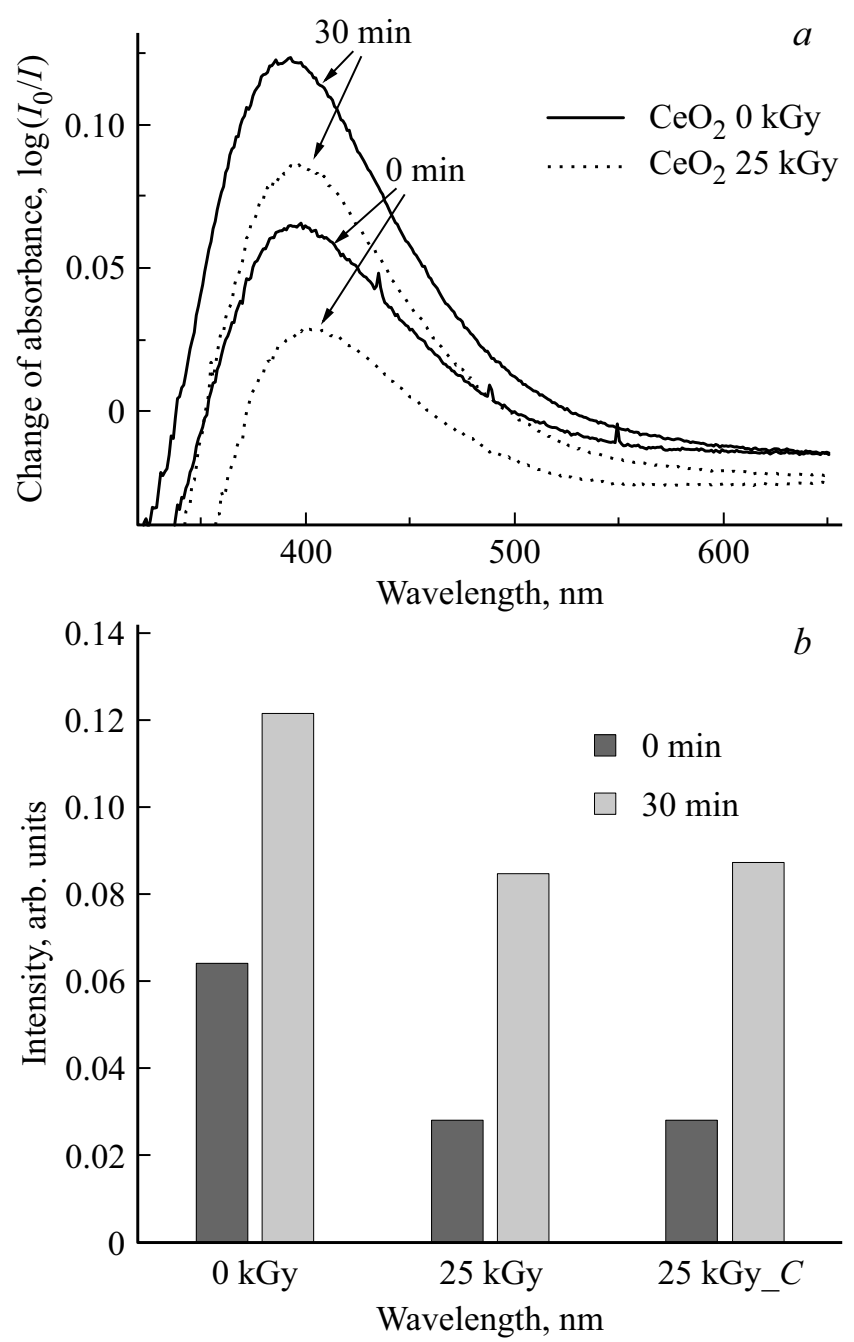

Рис. 5. $a-$ разностные спектры оптического поглощения для суспензий наночастиц $\mathrm{CeO}_{2}$ сразу после добавления $\mathrm{H}_{2} \mathrm{O}_{2}$ и через $30 \mathrm{~min}$ после добавления $\mathrm{H}_{2} \mathrm{O}_{2} ; b$ - относительное изменение оптической плотности образцов в области $400 \mathrm{~nm}$ после добавления $\mathrm{H}_{2} \mathrm{O}_{2}$ : $0 \mathrm{kGy}-$ необлученный образец, $25 \mathrm{kGy}$ - суспензия, приготовленная из облученного нанопорошка дозой $25 \mathrm{kGy}, 25 \mathrm{kGy \_ C}-$ облученная водная суспензия нанопорошка дозой $25 \mathrm{kGy}$. 
в области 300-450 nm с широким максимумом в области $360-380 \mathrm{~nm}$.

На рис. 4 представлены нормированные спектры ФЛ суспензий наночастиц оксида церия $\left(\lambda_{\mathrm{ex}}=250 \mathrm{~nm}\right)$, измеренные для разных режимов облучения дозой $25 \mathrm{kGy}$ : 1 - водная суспензия, приготовленная из заранее облученного нанопорошка, 2 - облученная водная суспензия. Видно, что при непосредственном облучении водной суспензии наночастиц наблюдается сдвиг максимума полосы фотолюминесценции в длинноволновую часть спектра ( 420-430 nm).

На рис. 5 представлены разностные спектры оптического поглощения суспензий наночастиц $\mathrm{CeO}_{2}$ сразу после добавления $\mathrm{H}_{2} \mathrm{O}_{2}$ и через $30 \mathrm{~min}$ после добавления $\mathrm{H}_{2} \mathrm{O}_{2}(a)$, а также гистограмма $(b)$, характеризующая относительное изменение оптической плотности образцов в области $400 \mathrm{~nm}$ после добавления $\mathrm{H}_{2} \mathrm{O}_{2}$ : $0 \mathrm{kGy}$ - необлученный образец, $25 \mathrm{kGy}$ - суспензия, приготовленная из облученного нанопорошка дозой $25 \mathrm{kGy}, 25 \mathrm{kGy \_ C}-$ облученная водная суспензия нанопорошка дозой $25 \mathrm{kGy}$. После добавления перекиси водорода оптическая плотность в области $400 \mathrm{~nm}$ начинает увеличиваться как для необлученного, так и для облученных образцов. Однако облученные образцы характеризуются замедлением реакции, обуславливающей возрастание оптического поглощения.

\section{4. Обсуждение результатов}

\section{1. Оптические переходы}

Неравновесные условия газофазного синтеза наночастиц методом испарения электронным пучком могут приводить к выраженной кислородной нестехиометрии диоксида церия. При испарении в вакууме за счет неравновесной кристаллизации наночастиц на холодной подложке реализуются соответствующие условия для образования значительного количества структурных дефектов в наночастицах. Наши ранние работы $[18,19]$ указывают на прямую связь различных физико-химических свойств наночастиц оксидов металлов, полученных данным методом, с их дефектной структурой. Некоторые дефектные центры обладают оптической активностью и могут быть обнаружены методами оптической спектроскопии. Для наночастиц оксида церия характерно формирование следующих дефектов: кислородные вакансии и связанные с ними $F^{0}, F^{+}$и $F^{++}$-центры, ионы $\mathrm{Ce}^{3+}$, ассоциированные с наличием кислородных вакансий, комплексы с переносом заряда $\mathrm{Ce}^{4+}-\mathrm{O}^{2-}[14]$. Данные центры являются оптически активными, однако идентификация ионов $\mathrm{Ce}^{3+}$ и кислородных вакансий в спектре поглощения затруднена вследствие суперпозиции полос этих центров с широкой полосой с переносом заряда $\mathrm{Ce}^{4+}-\mathrm{O}^{2-}$ в области $250-500 \mathrm{~nm}$.

При облучении нанопорошков наблюдается уменьшение величины оптической плотности в области 250-350 nm, что может свидетельствовать о деградации оптически активных центров, поглощающих в данной области. Кроме того, наблюдается смещение края фундаментального поглощения, которое может быть обусловлено изменением ширины запрещенной зоны нанокристалла.

Ширину запрещенной зоны $E_{g}$ нанокристалла можно определить по краю основной полосы оптического поглощения. Использование данного метода является предпочтительным (по сравнению с методами определения $E_{g}$ по температурной зависимости носителей заряда или по спаду фотопроводимости), так как не предъявляется особых требований к форме и размерам образца и обеспечивается достаточно высокая точность [22].

При переходе электрона из валентной зоны в зону проводимости под действием кванта света возможны два типа переходов - прямые переходы, в которых участвует только фотон и электрон, и непрямые переходы, в которых кроме фотона и электрона участвуют фононы. Ширину запрещенной зоны можно оценить по зависимости коэффициента поглощения $\alpha$ от энергии кванта света $h v[23]$ :

$$
\alpha h v=C\left(h v-E_{g}\right)^{n},
$$

где $n=1 / 2$ - для прямых переходов, $n=2-$ для непрямых переходов.

Коэффициент поглощения $\alpha$ может быть рассчитан по уравнению [23]:

$$
\alpha=2.3 \cdot 10^{3} \frac{D \cdot \rho}{l \cdot C}
$$

где $D-$ оптическая плотность $\left(D=\log \frac{I_{0}}{I}\right.$, где $I_{0}$ и $I$ - интенсивности света до и после взаимодействия с образцом), $C=0.2 \mathrm{~g} / 1-$ концентрация нанопорошка в суспензии, $l=10 \mathrm{~mm}$ - длина оптического пути, $\rho=7.28 \mathrm{~g} / \mathrm{cm}^{3}$ - плотность нанокристалла $\mathrm{CeO}_{2}$.

Расчет ширины запрещенной зоны нанокристалла производился графическим методом Тауца [20]. На графике $(\alpha h v)^{2}=f(h v)$ был выявлен наиболее крутой участок, где экспериментальные точки удовлетворяют линейной зависимости. Экстраполяция этого участка на ось абсцисс дает значение ширины запрещенной зоны нанокристалла. Рассчитанное таким образом значение ширины запрещенной зоны для необлученного нанопорошка $E_{g}=3.24 \mathrm{eV}$ - находится в согласии с литературными данными [24]. В случае непрямых переходов зависимость коэффициента поглощения от энергии фотона носит более сложный характер, который в общем случае может быть описан функцией: $(\alpha \cdot h v)^{1 / 2}=f(h v)$. Рассчитанное данным образом значение для необлученного нанопорошка $E_{g}=2.0 \mathrm{eV}$. Результаты расчетов $E_{g}$ для необлученного и облученных нанопорошков приведены в таблице. Край фундаментального поглощения (рис. 1) не является резким, поэтому можно сделать вывод, что для НЧДЦ наночастицы диоксида церия характерны непрямые оптические переходы [25].

При облучении дозами выше $25 \mathrm{kGy}$ наблюдается тенденция к уменьшению ширины запрещенной зоны 
для прямых и непрямых переходов (см. таблицу). Предполагается, что это связано с уменьшением доли ионов $\mathrm{Ce}^{3+}$ на поверхности наночастиц [23].

\section{2. Люминесцентные свойства}

Матричный металлический ион церия в наночастицах $\mathrm{CeO}_{2}$ имеет валентность $4+$ и не проявляет люминесцентных свойств. Однако во время синтеза возможно формирование дефектов кристаллической решетки кислородных вакансий и ассоциированных с ними ионов $\mathrm{Ce}^{3+}$. Данные центры являются оптически активными и проявляют люминесцентные свойства $[11,14]$. Вероятно, наблюдаемая нами ФЛ с максимумом в области $360-380 \mathrm{~nm}$ обусловлена суперпозицией полос свечения подобных центров. Кроме того, для оксида церия характерно проявление люминесценции, связанной со свечением комплексов с переносом заряда $\mathrm{Ce}^{4+}-\mathrm{O}^{2-}$, однако вследствие сильной реорганизации зарядовой плотности данное свечение наблюдается зачастую только при низких температурах [11].

При облучении нанопорошков наблюдается снижение интенсивности люминесценции, в то время как профиль кривых остается практически неизменным. Характер зависимости интенсивности свечения от дозы облучения коррелирует с изменениями спектров оптического поглощения облученных образцов, что подтверждает наше предположение о суперпозиции полос поглощения оптически активных центров и комплексов с переносом заряда в области 250-400 nm. Облучение нанопорошков в выбранном диапазоне доз $12.5-50 \mathrm{kGy}$, вероятно, привело к деградации оптических центров, ответственных за люминесценцию, наблюдаемую при комнатной температуре.

Облучение наночастиц в разных режимах (до и после приготовления суспензий) приводит к смещению максимума полосы фотолюминесценции (рис. 4). Подобное изменение спектров люминесценции наблюдали в [26] при изучении взаимодействия наночастиц с перекисью водорода. Перед добавлением перекиси водорода максимум пика ФЛ наблюдался в области $\sim 450 \mathrm{~nm}$, в то время как после добавления $\mathrm{H}_{2} \mathrm{O}_{2}$ в спектре ФЛ появлялся новый пик в области $\sim 360 \mathrm{~nm}$, интенсивность которого сначала увеличивалась, а потом уменьшалась до исходного состояния. Предполагается, что появление пика ФЛ в коротковолновой части спектра $(\sim 360 \mathrm{~nm})$ связано с окислением ионов $\mathrm{Ce}^{3+}$ до состояния $\mathrm{Ce}^{4+}$ в результате взаимодействия с $\mathrm{H}_{2} \mathrm{O}_{2}$, тогда как пик ФЛ в области $\sim 450 \mathrm{~nm}$ ассоциирован с восстановленными ионами $\mathrm{Ce}^{3+}[26]$.

На основании проведенного анализа можно предположить, что облучение водной суспензии приводит к формированию оптически активных дефектов, ассоциированных с ионами $\mathrm{Ce}^{3+}$, что обуславливает сдвиг максимума ФЛ в длинноволновую область. По сравнению с этим облучение нанопорошков и дальнейшее приготовление водных суспензий на их основе представляет собой многостадийный процесс, в результате которого поверхность наночастиц успевает окислиться и количество ионов $\mathrm{Ce}^{4+}$ на поверхности наночастиц увеличивается.

В дальнейшем для модификации наночастиц оксида церия $\mathrm{CeO}_{2}$ с целью увеличения соотношения $\mathrm{Ce}^{3+} / \mathrm{Ce}^{4+}$ на поверхности наночастиц целесообразно облучать именно водные суспензии с последующим осаждением и отжигом нанопорошка, как описано в [16].

\section{3. Каталазаподобная активность наночастиц}

Многочисленные исследования биологической активности оксида церия $\mathrm{CeO}_{2}$ посвящены исследованиям имитации поведения ферментов, в особенности, каталазы и супероксиддисмутазы [7,27]. Исследуемые наночастицы $\mathrm{CeO}_{2}$ имеют квазисферическую полиэдральную форму, и поэтому они могут проявлять каталазоподобную активность и ингибировать перекись водорода [27].

На рис. 5 представлены разностные спектры оптического поглощения сразу после добавления перекиси водорода $\mathrm{H}_{2} \mathrm{O}_{2}$ и через $30 \mathrm{~min}$ после добавления реагента. Добавление $\mathrm{H}_{2} \mathrm{O}_{2}$ приводит к увеличению оптического поглощения в диапазоне $300-450 \mathrm{~nm}$, которое сначала увеличивается, а затем с течением времени уменьшается к исходному состоянию. Увеличение оптического поглощения в данной области можно объяснить взаимодействием перекиси водорода с ионами $\mathrm{Ce}^{3+}$, что приводит к образованию ионов $\mathrm{Ce}^{4+}$. Через некоторое время ионы $\mathrm{Ce}^{4+}$ восстанавливаются до состояния $\mathrm{Ce}^{3+}$, а поглощение в диапазоне $300-450 \mathrm{~nm}$ уменьшается [7,26]. Подобная активность наночастиц оксида церия наблюдается в нейтральных и щелочных средах. Среды с пониженным значением $p \mathrm{H}$, наоборот, ингибируют каталазоподобную активность $\mathrm{CeO}_{2}$. Данное поведение наночастиц оксида церия в средах с разной кислотностью является основой для объяснения дифференциальной цитотоксичности материала по отношению к тканям с разным значением $p \mathrm{H}$ [28].

После облучения наночастиц $\mathrm{CeO}_{2}$ независимо от режима облучения наблюдается снижение скорости реакции, имитирующей каталазаподобную активность (рис. 5), что косвенно подтверждает гипотезу о корреляции люминесцентных свойств материала и проявляемой им биологической активности.

\section{5. Заключение}

В настоящей работе исследовались наночастицы оксида церия $\mathrm{CeO}_{2}$, полученные путем испарения импульсного электронного пучка в газе низкого давления. Нанопорошки $\mathrm{CeO}_{2}$ были облучены ускоренными электронами с целью изменения валентного соотношения $\mathrm{Ce}^{3+} / \mathrm{Ce}^{4+}$ на поверхности наночастиц. Исследование наночастиц оксидов церия проводилось с использованием методов оптической и люминесцентной спектроскопии. Выбор методов объясняется необходимостью обнаружения связанных оптически активных люминесцентных центров, 
формирование которых, вероятно, объясняет биологическую активность материалов.

Для исследуемого материала обнаружено формирование оптически активных центров, ответственных за оптическое поглощение в УФ-области и наблюдаемую люминесценцию. Данные дефекты, вероятно, имеют природу, связанную с кислородными вакансиями и ассоциированными с ними ионами $\mathrm{Ce}^{3+}$. Формирование данных центров связано, в первую очередь, с неравновесными условиями газофазного синтеза наночастиц. Модификация наночастиц электронным пучком приводит к деградации данных центров и проявляется в снижении оптической плотности образцов в УФ-диапазоне и интенсивности люминесценции с увеличением дозы облучения.

Сравнение разных режимов облучения (нанопорошка или готовой водной суспензии) позволяет сделать предварительный вывод, что наиболее эффективная модификация оксида церия ионизирующим излучением с целью увеличения соотношения $\mathrm{Ce}^{3+} / \mathrm{Ce}^{4+}$, вероятно, реализуется при облучении готовой водной суспензии с последующим осаждением нанопорошка.

Наночастицы $\mathrm{CeO}_{2}$ проявляют каталазаподобную активность при взаимодействии с перекисью водорода, однако в облученных порошках данная активность снижена. Данное заключение позволяет предположить, что оптически активные дефекты, ответственные за наблюдаемую люминесценцию, участвуют в процессах инактивации перекиси водорода

\section{Список литературы}

[1] А.Б. Щербаков, Н.М. Жолобак, В.К. Иванов. Ю.Д. Третьяков, Н.Я. Спивак. Биотехнологии 4, 9 (2011).

[2] S. Das, J.M. Dowding, K.E. Klump, J.F. Mcginnis, W. Self, S. Seal. Nanomedicine 8, 1483 (2013).

[3] J. Kaspar, P. Fornasiero, M. Graziani. Catalysis Today 50, 285 (1999).

[4] P. Jasinski, T. Suzuki, H.U. Anderson. Sensors Actuators B 95, 73 (2003).

[5] C.W. Sun, R. Hui, J. Roller. J. Solid State Electrochem. 14, 1125 (2010).

[6] В.К. Иванов, А.Б. Щербаков, А.В. Усатенко. Успехи химии 78, 924 (2009).

[7] E.G. Heckert, A.S. Karakoti, S. Seal, W.T. Self. Biomaterials 29, 2705 (2008).

[8] Y. Xue, Q. Luan, D. Yang. J. Phys. Chem. C 115, 4433 (2011).

[9] S. Saitzek, J.F. Blach, S. Villain. Phys. Status Solidi 205, 1534 (2008).

[10] А.О. Стоянов, В.К. Иванов, А.Б. Щербаков, И.В. Стоянова, Н.А. Чивирева, В.П. Антонович. Журн. неорган. химии 59, 139 (2014).

[11] П.О. Максимчук, О.Г. Вагин, И.И. Беспалова, А.А. Маслова, Н.И. Спивак, Ю.В. Малюкин. Биофиз. вестн. 28, 68 (2012).

[12] L. He, Y. Su, L. Jiang, A. Shi. J. Rare Earths 33, 791 (2015).

[13] K.K. Babitha, A. Sreedevi, K.P. Priyanka, B. Sobu, T. Varghese. Ind. J. Pure Appl. Phys. 53, 596 (2015).
[14] E.N. Okrushko, V.V. Seminko, P.O. Maksimuchuk, I.I. Bespalova, N.V. Kononets, O.G. Viagin, Yu.V. Malyukin. Low Temper. Phys. 43, 636 (2017).

[15] K.K. Babitha, K.P. Priyanka, A. Sreedevi, S. Ganesh, T. Varghese. Mater. Character. 98, 222 (2014).

[16] M.M. Khan, S.A. Ansari, D. Pradhan, D.H. Han, J. Lee, M.H. Cho. Industr. Eng. Chem. Res. 53, 9754 (2014).

[17] S.Yu. Sokovnin, M.E. Balezin, V.G. Ilves. Mater. Chem. Phys. 215, 127 (2018).

[18] В.Г. Ильвес, С.Ю. Соковнин. Рос. нанотехнологии 7, 34 (2012).

[19] S.Yu. Sokovnin, V.G. Ilves, M.G. Zuev. Eng. Nanobiomater. Appl. Nanobiomater. 2, 29 (2016).

[20] J. Tauc. Mater. Res. Bull. 3, 37 (1968).

[21] A. Medalia, B. Byrne. Anal Chem. 23, 453 (1951).

[22] Л.П. Павлов. Методы измерения параметров полупроводниковых материалов. Высш. шк., М. (1987). 239 с.

[23] Z. Wang, Z. Quan, J. Lin. Inorg. Chem. 46, 5237 (2007).

[24] S. Phoka, P. Laokul, E. Swatsitang, V. Promarak, S. Seraphin, S. Maensiri. Mater. Chem. Phys. 115, 423 (2009).

[25] E. Rosencher, B. Vinter. Optoelectronics. Cambridge University Press. ISBN: 0521771293.

[26] B.A. Rzigalinski, K. Meeban, R.M. Davis, Y. Xu, W.C. Miles, C.A. Cohen. Nanomedicine 1, 399 (2006).

[27] T. Naganuma. Nano Res. 10, 199 (2017).

[28] L.E. Gerweek, K. Seetharaman. Cancer Res. 56, 1194 (1996).

Редактор Д.В. Жуманов 